\title{
Over-expression of a protein kinase gene enhances the defense of tobacco against Rhizoctonia solani
}

\author{
Osmany Chacón ${ }^{\mathrm{a}, \mathrm{b}}$, Marleny González ${ }^{\mathrm{a}, \mathrm{c}}$, Yunior López ${ }^{\mathrm{a}}$, Roxana Portieles ${ }^{\mathrm{a}}$, Merardo Pujol ${ }^{\mathrm{a}}$, \\ Ernesto González ${ }^{\mathrm{a}}$, Henk-Jan Schoonbeek ${ }^{\mathrm{d}}$, Jean-Pierre Métraux ${ }^{\mathrm{d}}$, Orlando Borrás-Hidalgo ${ }^{\mathrm{a}, *}$ \\ a Laboratory of Plant Functional Genomics, Center for Genetic Engineering and Biotechnology, P.O. Box 6162, Havana, 10600, Cuba \\ b Tobacco Research Institute. Carretera de Tumbadero 8, P.O. Box 6063, San Antonio de los Baños, Havana, Cuba \\ c Plant Health Institute, Playa, Havana, 11600, Cuba \\ d Department of Biology, University of Fribourg, Chemin du Musée 8, CH-1700 Fribourg, Switzerland
}

\begin{abstract}
To identify Nicotiana tabacum genes involved in resistance and susceptibility to Rhizoctonia solani, suppression subtractive hybridization was used to generate a cDNA library from transcripts that are differentially expressed during a compatible and incompatible interaction. This allowed the isolation of a protein kinase cDNA that was down-regulated during a compatible and up-regulated during an incompatible interaction. Quantitative RT-PCR analysis of this gene confirmed the differential expression patterns between the compatible and incompatible interactions. Over-expression of this gene in tobacco enhanced the resistance to damping-off produced by an aggressive $R$. solani strain. Furthermore, silencing of this protein kinase gene reduced the resistance to a non-aggressive $R$. solani strain. A set of reported tobaccoresistant genes were also evaluated in tobacco plants over-expressing and silencing the protein kinase cDNA. Several genes previously associated with resistance in tobacco, like manganese superoxide dismutase, Hsr203J, chitinases and phenylalanine ammonia-lyase, were up-regulated in tobacco plants over-expressing the protein kinase cDNA. Potentially, the protein kinase gene could be used to engineer resistance to $R$. solani in tobacco cultivars susceptible to this important pathogen.
\end{abstract}

\section{Introduction}

Rhizoctonia solani J.G. Kühn (teleomorph Thanatephorus cucumeris (A.B. Frank) Donk) can cause serious disease problems in both transplant and field production of tobacco. This pathogen became more of a problem on seedlings in the 1990s as tobacco growers largely switched from the production of transplants in outdoor plant beds to greenhouse float systems (Elliott et al. 2008).

$R$. solani causes damping-off and stem rot in young transplants and a disease of the lower stem and root called sore shin in older field plants (Lucas, 1975, Sneh et al. 1996). This disease can result in seedling death in the greenhouse and moderate to severe stunting and death of plants in the field. Transplanting infected seedlings is a major cause of sore shin in field plants; however, infection also can be caused by $R$. solani that is already present in the field (Elliott et al. 2008).

Target spot is a foliar disease that first appeared in the United States in the 1980s and is an economically important disease in tobacco production (Shew, 1991, Elliott et al. 2008). This disease is caused by infection with basidiospores of $T$. cucumeris which are

\footnotetext{
* Corresponding author. Tel.: +537 2716022; fax: +537 2731779

E-mail address: orlando.borras@cigb.edu.cu (O. Borrás-Hidalgo).
}

produced on hymenia that form on the soil surface or infected plant tissue (Shew and Main, 1990, Elliott et al. 2008). Symptoms begin as small water-soaked lesions on the leaves which can expand to large circular spots with concentric rings. This disease occurs on tobacco seedlings in greenhouse environments and usually is observed after the leaves of the seedlings have grown close enough to form a canopy, forming a high-humidity environment that favors disease development (Elliott et al. 2008). In severe cases, the pathogen may grow from the leaf tissue into the stem, resulting in plant death (Elliott et al. 2008). Isolates of $R$. solani causing stem and root rot symptoms have been characterized by anastomosis as groups AG-1, AG-2-2, and AG-4, whereas target spot in the greenhouse and the field as group AG-3 (Stevens et al. 1993).

Resistance to $R$. solani in tobacco cultivars would be highly desirable, but previous screenings for resistance in the tobacco germplasm have been limited to a small number of commonly used cultivars. However, evaluation of germplasm and identification of resistance to $R$. solani has been successful in other crops such as peanut, bean, rice, sorghum, and sugar beet (Francke et al. 1999, Montoya et al. 1997, Pan et al. 1999; Pascual et al. 2000, Scholten et al. 2001). Recently, 57 genotypes composing several classes of tobacco and related Nicotiana spp. were evaluated for resistance to seedling stem rot and target spot (Elliott et al. 2008). Significant differences in 
disease incidence were only observed at a low disease pressureamong the genotypes for both stem rot and target spot. However, resistance to target spot was not observed when disease pressure was high while partial resistance to stem rot was observed in several genotypes in repeated tests (Elliott et al. 2008).

Several constitutive factors have been associated with resistance to R. solani, including epicuticular wax thickness (Marshall and Rush, 1980), cuticle thickness (Reddy, 1980), and cell wall calcium content (Bateman, 1964, Bateman and Lumsden, 1965). The cuticle and epicuticular wax hinders the action of pathoenzymes or toxins released by Rhizoctonia spp., thus participating in the tolerance to the pathogen (Kenning and Hanchey, 1980). In addition, induced resistance mechanisms such as the hypersensitive response (Marshall and Rush, 1980) or an increase in the production of PR proteins may also be involved in resistance (Anuratha et al. 1996).

However, little is known about molecular events associated with resistance to $R$. solani in tobacco. Recently, a decrease in resistance to a compatible strain of $R$. solani was observed in type III knockdown tobacco lines targeted at the calmodulin (CaM) NtCaM13. The expression of jasmonic acid (JA) and/or ethylene (ET)-inducible basic PR genes was not affected in this line, suggesting that type III CaM isoforms are probably involved in basal defense against necrotrophic pathogens independently of JA and ET signaling (Takabatake et al. 2007).

To gain insight in the molecular components that are responsible for the establishment of the susceptibility and resistance of Nicotiana tabacum to $R$. solani, a suppression subtractive hybridization (SSH) approach was used to generate cDNA libraries containing transcript derived fragments from $N$. tabacum genes that are respectively induced or repressed during a compatible or incompatible interaction with $R$. solani. Candidates were then evaluated using over-expression and RNAi approaches in N. tabacum. This approach has identified a $N$. tabacum protein kinase gene (NtPK) that could provide resistance to aggressive strains of $R$. solani in $N$. tabacum.

\section{Materials and methods}

\subsection{Fungal and plant materials, and infection assays}

The N. tabacum cv. 'Sumatra' plants (provided by the Tobacco Research Institute, Cuba) were grown from seeds in 6-in. pots containing black turf and rice husk (4:1) and maintained in growth chambers at $23^{\circ} \mathrm{C}$. Aggressive (RF) (kindly supplied by Dr. Bruno P. A. Cammue) and nonaggressive (RS10) isolates from anastomosis group 4 of $R$. solani were collected from infected tobacco plants and used for the inoculations. The nonaggressive isolate did not cause any symptoms in inoculated $N$. tabacum cv. 'Sumatra' plants (data not shown). The isolates were grown on potato dextrose agar at room temperature $\left(22{ }^{\circ} \mathrm{C}\right.$ to $25^{\circ} \mathrm{C}$ ) for 5 days. Colonized agar plugs were removed and transferred to 250-ml Erlenmeyer flasks containing autoclaved rice grains (Shew and Main 1990). The pathogen was allowed to thoroughly colonize the rice grains for approximately 2 weeks at room temperature prior to use for inoculations. Two-week-old tobacco seedlings were inoculated with the pathogen placing infested rice (approximately six grains) onto the surface of the soil according to Elliott et al. (2008). Mock-inoculated N. tabacum cv. 'Sumatra' plants were used as controls. The interaction between the aggressive isolate with N. tabacum cv. 'Sumatra' plants was named as compatible. Meanwhile, the interaction between the nonaggressive isolate with N. tabacum cv. 'Sumatra' plants was named as incompatible.

\subsection{Assessment of the infection progress}

Typical symptoms caused by aggressive and nonaggressive $R$. solani isolates were monitored visually on N. tabacum cv. 'Sumatra' plants at $0,1,2$, and 3 weeks postinoculation (wpi). At the same time points, growth of $R$. solani on tobacco was estimated by quantitative real-time reverse transcription-PCR. The extent of colonization was determined by the ratio of transcripts of the constitutively expressed actin gene (measure for fungal biomass) to the constitutively expressed tobacco 26S rRNA gene (measure for plant biomass) shown on a logarithmic scale. For each time point, three root samples were taken from five plants, and the experiment was repeated twice.

\subsection{Construction of the suppression subtractive libraries}

Root and stem material were collected from $20 \mathrm{~N}$. tabacum cv. 'Sumatra' plants inoculated with aggressive and nonaggressive $R$. solani isolates at 1, 2, and 3 wpi and pooled before RNA extraction. These materials were used to generate the "tester" sample. For the "driver" sample, plant materials from mock-inoculated plants harvested at the same time points were used. After subtractive hybridization, two cDNA libraries were obtained containing aggressive and nonaggressive $R$. solani-induced $N$. tabacum cv. 'Sumatra' genes (forward-subtraction). To generate the cDNA libraries with the repressed genes, the "tester" was used as "driver" and the "driver" was used as "tester" (reverse-subtraction). Thus, after subtractive hybridization, two cDNA libraries were obtained containing aggressive and nonaggressive $R$. solani-repressed $N$. tabacum cv. 'Sumatra' genes. The total RNA was extracted using RNeasy Plant Mini Kit (Qiagen, Maryland, USA). Poly (A) + RNA was isolated using Oligotex mRNA kits Mini (Qiagen, Maryland, USA), according to the manufacturer's instructions. Finally, double-stranded cDNA was synthesized according to PCR-Select subtractive hybridization kit (Clontech, Palo Alto, CA, USA). The subtracted cDNA libraries were constructed by subtractive hybridization using the PCR-Select subtractive hybridization kit. The subtracted libraries were cloned into the pGEM-T easy vector (Promega, Madison, WI, USA) according to manufacturer's instructions. Colonies were picked and grown in 96-well microtiter plates in LB medium containing $100 \mathrm{mg} / \mathrm{L}$ ampicillin. All clones were PCR-amplified using the nested primers 1 and 2R (Clontech, Palo Alto, CA, USA) to check the presence and size of the individual inserts.

\subsection{DNA sequencing and sequence data analysis}

DNA sequencing was performed using an automated ABI Model 377 DNA sequencer (Applied Biosystems, Warrington, UK). The procedures were performed according to the manufacturer's instructions. The M13 forward and reverse primers were used to generate sequences for all cDNAs isolated (Perkin Elmer ABI PRISM Dye Terminator Cycle sequencing kit) and the sequences were submitted to GenBank (accession numbers G0944000-G0944095). Homologies of the cDNA sequences with database sequences were determined

Table 1

List of primers used in real-time RT-PCRs.

\begin{tabular}{|c|c|c|}
\hline Target gene & Primers & $\begin{array}{l}\text { Product size } \\
\text { (bp) }\end{array}$ \\
\hline N. tabacum protein kinase & $\begin{array}{l}5^{\prime}-\text { ttctcagtcggggataatgc }-3^{\prime} \\
5^{\prime} \text { - cactgtggaataggcaagca }-3^{\prime}\end{array}$ & 126 \\
\hline $\begin{array}{l}\text { N. tabacum manganese } \\
\text { superoxide dismutase }\end{array}$ & $\begin{array}{l}5^{\prime}-\text { cgacactaactttggctccctaga }-3^{\prime} \\
5^{\prime}-\text { acgtctattcccagaagaggaacc }-3^{\prime}\end{array}$ & 192 \\
\hline N. tabacum $\beta-1,3$ glucanase & $\begin{array}{l}5^{\prime}-\text { gccagatttctctcccctattctc }-3^{\prime} \\
5^{\prime} \text { - actctcggacacaacaatccctac }-3^{\prime}\end{array}$ & 161 \\
\hline N. tabacum Hsr203J & $\begin{array}{l}5^{\prime} \text {-aggaagtatccggctggcttaga }-3^{\prime} \\
5^{\prime} \text {-gaagtagtcatggggtgggactg }-3^{\prime}\end{array}$ & 113 \\
\hline N. tabacum chitinases & $\begin{array}{l}5^{\prime}-\text { gggttactgctggcttagagaaca }-3^{\prime} \\
5^{\prime}-\text { tgtttaggaggtccactcctatgg }-3^{\prime}\end{array}$ & 170 \\
\hline $\begin{array}{l}\text { N. tabacum phenylalanine } \\
\text { ammonia-lyase }\end{array}$ & $\begin{array}{l}5^{\prime} \text { - ggacaagggcagctatgctagtta }-3^{\prime} \\
5^{\prime} \text { - cattgagggtctcaccattaggtc }-3^{\prime}\end{array}$ & 237 \\
\hline N. tabacum 26S rRNA & $\begin{array}{l}5^{\prime} \text {-cacggaccaaggagtctgacat-3' } \\
5^{\prime} \text {-tcccaccaatcagcttccttac-3' }\end{array}$ & 150 \\
\hline
\end{tabular}




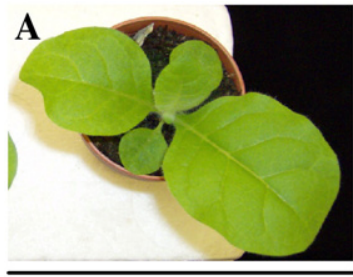

0

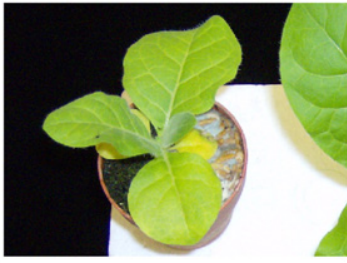

1

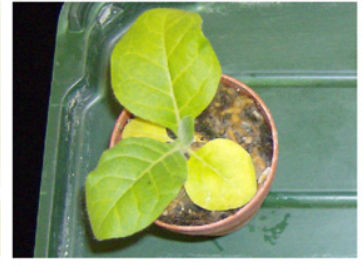

2

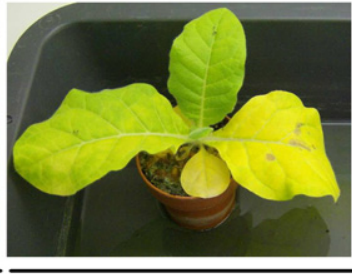

3

Time (weeks post inoculation)

B

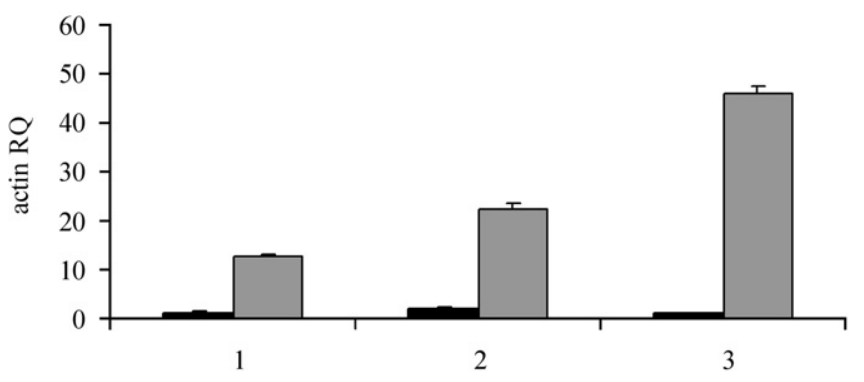

Time (weeks post inoculation)

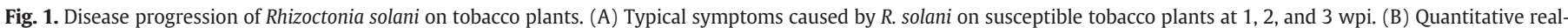

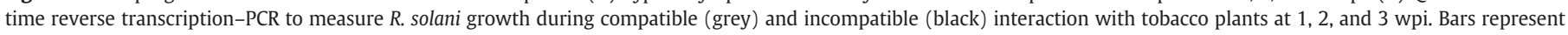
mean values $(N=5 ; \pm \mathrm{SD})$.

using BLASTX and BLASTN homology searches (Altschul et al. 1997). $E$-value scores below $10^{-5}$ were considered as significant and used to indicate homology between tobacco sequences and database sequences. Those cDNA clones silenced in the compatible interaction and, at the same time, expressed in the incompatible interaction, were selected for further studies.

\subsection{Real-time PCR analyses}

In a separate experiment, total RNA was extracted from $N$. tabacum cv. 'Sumatra' plants inoculated with both aggressive and nonaggressive $R$. solani isolates at $0,1,2$, and 3 wpi using the RNeasy Plant Mini kit (Qiagen, Maryland, USA) according to manufacturer's instruction. Poly (A) + RNA was isolated using Oligotex mRNA kits Mini (Qiagen, Maryland, USA), according to the manufacturer's instructions. The cDNA were synthesized using an oligo-(dT) primer and the SuperScript III reverse transcriptase kit (Invitrogen, Carlsbad, CA) according to the manufacturer's instructions. Quantitative real-time PCR was conducted using a Rotor-Gene 3000 PCR machine (Corbett, Australia) with the QuantiTect SYBR Green PCR Kit (Qiagen). All primer sequences were designed according to Primer 3 online software and shown in Table 1. Real-time PCR conditions were as follows: an initial $95{ }^{\circ} \mathrm{C}$ denaturation step for $15 \mathrm{~min}$ followed by denaturation for $15 \mathrm{~s}$ at $95{ }^{\circ} \mathrm{C}$, annealing for $30 \mathrm{~s}$ at $60{ }^{\circ} \mathrm{C}$, and extension for $30 \mathrm{~s}$ at $72{ }^{\circ} \mathrm{C}$ for 40 cycles and analyzed on the RotorGene 3000 software (Corbett, Australia). Two biological replicates for each sample were used for real-time PCR analysis, and three technical replicates were analyzed for each biological replicate.

\subsection{Overexpression of protein kinase gene in tobacco plants}

The full-length coding region for NtPK gene was obtained according to specifications in the SMART RACE II kit (BD Clontech). The coding region of the NtPK gene cloned in pBluescript vector was digested with $\mathrm{Ncol} / \mathrm{Smal}$ and ligated into the $\mathrm{pBP} \Omega 8$ vector between the cauliflower mosaic virus (CaMV) 35S promoter and the nopaline synthase terminator (T nos). The resulting CaMV 35 S promoter/NtPK/ $\mathrm{T}$ nos fusions were inserted into the HindIII/PstI site of the binary T-DNA plasmid, pCambia 2300 (kindly supplied by Prof. Richard Jefferson, CAMBIA, Australia) for tobacco transformation (Fig. 2A). One construct was transferred to Agrobacterium tumefaciens strain At2260 using the liquid nitrogen method (Höfgen and Willmitzer, 1988). The transformation protocol was followed according to Ayala et al. (2009). Regenerated seedlings, all $5 \mathrm{~cm}$ in height, were transferred to pots containing black turf and rice husk (4:1) and grown in growth chambers at $23^{\circ} \mathrm{C}$.

Table 2

Relative expression of candidate genes identified in Nicotiana tabacum cDNA library.

\begin{tabular}{|c|c|c|c|c|c|c|c|c|}
\hline \multirow[t]{3}{*}{ Genes identified into the cDNA library } & \multicolumn{4}{|c|}{ Relative expression during compatible interaction ${ }^{a}$} & \multicolumn{4}{|c|}{ Relative expression during incompatible interaction } \\
\hline & \multicolumn{4}{|c|}{ Weeks postinoculation } & \multicolumn{4}{|c|}{ Weeks postinoculation } \\
\hline & 0 & 1 & 2 & 3 & 0 & 1 & 2 & 3 \\
\hline Protein kinase & 1.5 & 0.3 & 0.1 & 0.1 & 1.4 & 2.6 & 2.7 & 2.6 \\
\hline$\overline{\text { Cytochrome P450 like TBP }}$ & $\overline{2.1}$ & $\overline{2.2}$ & $\overline{2.4}$ & $\overline{2.2}$ & $\overline{2.2}$ & $\overline{2.3}$ & $\overline{2.3}$ & $\overline{2.2}$ \\
\hline Manganese superoxide dismutase & 1.5 & 2.5 & 2.6 & 2.7 & 1.5 & 2.6 & 2.6 & 2.7 \\
\hline Cell wall-associated hydrolase & 1.3 & 1.4 & 1.4 & 1.4 & 1.5 & 1.6 & 1.7 & 1.7 \\
\hline Mitogen-activated protein kinase & 1.5 & 3.2 & 3.3 & 3.4 & 1.6 & 3.5 & 3.5 & 3.6 \\
\hline Phospholipase B-like protein & 1.4 & 1.5 & 1.6 & 1.8 & 1.6 & 1.7 & 1.7 & 1.8 \\
\hline
\end{tabular}

${ }^{\mathrm{a}}$ Each measurement represents the mean relative expression from three independent experiments. Bold and underline font represent the gene and its relative expression selected

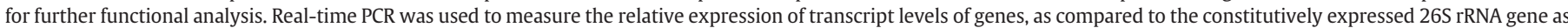
an endogenous control into independent experiments. 


\subsection{Construction of plasmids for RNAi in N. tabacum}

Sense and antisense NtPK gene (200 bp) was PCR-amplified from cDNA using forward and reverse primers that added the XhoI/BamHI (sense) and $\mathrm{KpnI} / \mathrm{Xbal}$ (antisense) restriction site, respectively (Table 1). PCRs were carried out under the following conditions: an initial denaturation step for 2 min followed by denaturation for
$15 \mathrm{~s}$ at $94{ }^{\circ} \mathrm{C}$, annealing for $30 \mathrm{~s}$ at $57^{\circ} \mathrm{C}$, and extension for $1 \mathrm{~min}$ at $72{ }^{\circ} \mathrm{C}$ for 30 cycles, followed by a final elongation step at $72{ }^{\circ} \mathrm{C}$ for 5 min. PCR products were separated on 1\% agarose gels and were purified using the DNeasy kit (Qiagen, Valencia, CA). Subsequently, PCR products were cloned into the $\mathrm{pBP} \Omega 8$ plasmid. This plasmid contained the castor bean catalase intron kindly supplied by Dr.

Wang (CSIRO, Australia). The resulting CaMV 35S promoter/sense
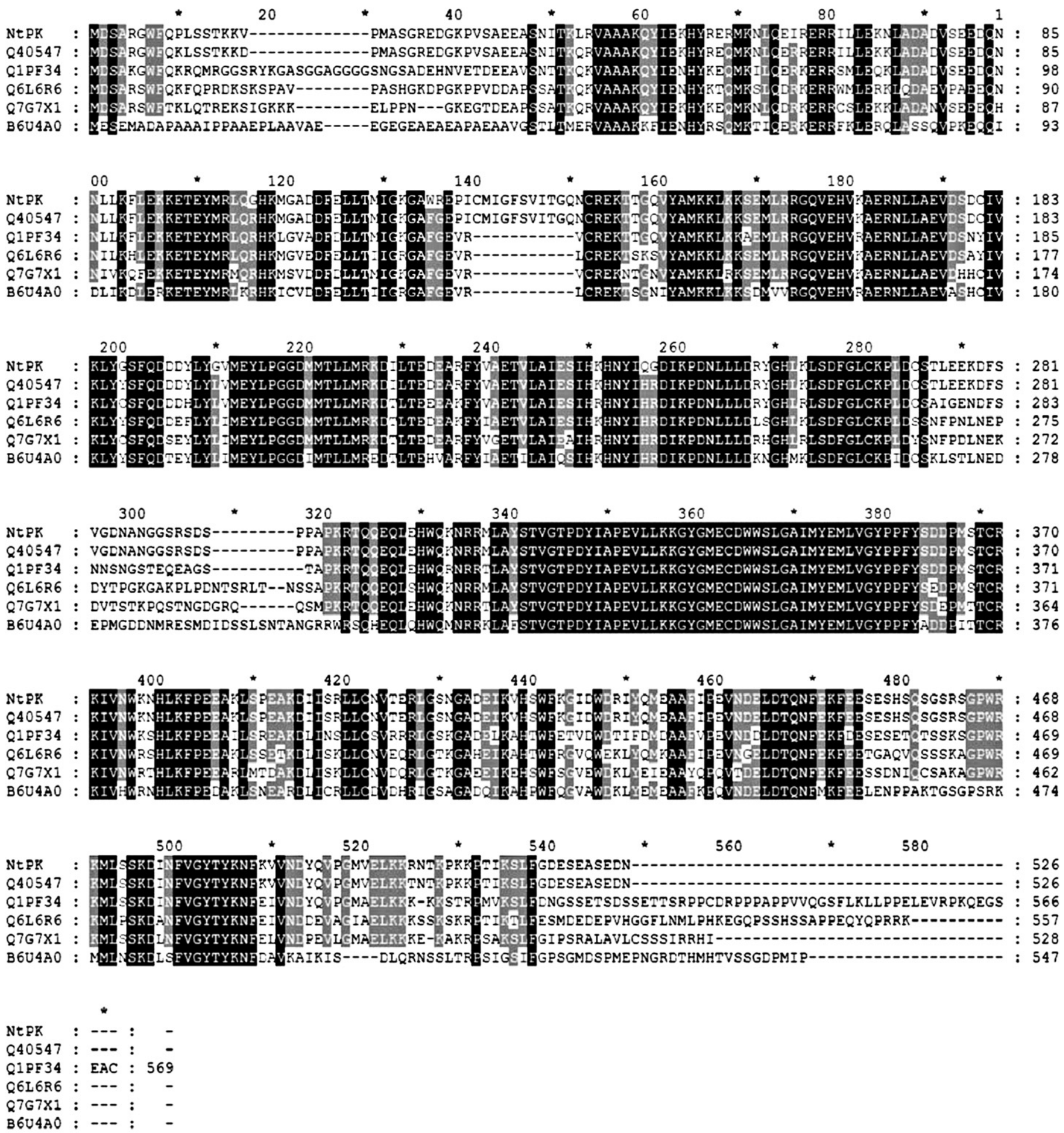

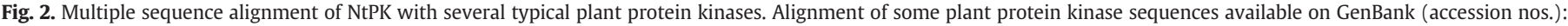

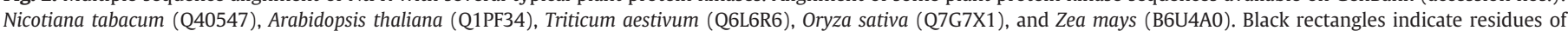

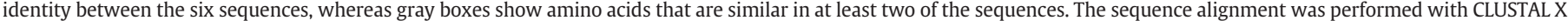
software (Thompson et al., 1997). 
$N t P K$, intron, antisense NtPK/T nos fusions were inserted into the site HindIII/PstI of the binary T-DNA plasmid, pCambia 2300 for tobacco transformation (Fig. 2B). Tobacco was transformed according to Ayala et al. (2009).

\subsection{Evaluation of disease resistance in transgenic lines}

Following transformation, the seedlings $\left(T_{0}\right)$ were inoculated with aggressive and nonaggressive isolates of $R$. solani, according to Elliott et al. (2008), to assess the role of the gene in the resistance. Additionally, quantitative real-time reverse transcription-PCR was used to measure the growth of $R$. solani. Disease incidence (percentage of plants exhibiting seedling death and stem rot) was determined according to Elliott et al. (2008). The resistance screen was conducted in a randomized complete block design with 30 transgenic lines per replicate from each construction (overexpression and RNAi approach) and five replications were used per experiment. An arcsine transformation was performed on percent incidence data before statistical analysis to improve homogeneity of variance.

\section{Results}

\subsection{Quantification of R. solani biomass in infected tobacco roots}

The first symptom of the infection by the aggressive $R$. solani strain was a small water-soaked lesion on the stem close to the soil line that rapidly becomes brown and sunken. The lesion continued to grow throughout the stem and leaves causing them to turn brown and die. Subsequently, the chlorosis on the foliar areas was not evident until 2 wpi (Fig. 1A).

Fungal biomass gradually increased while $R$. solani colonized the roots during a compatible interaction as quantified using real-time PCR (Fig. 1B). No disease symptoms were visible after inoculation with a nonaggressive $R$. solani isolate (not shown). Real-time PCR confirmed that no significant increase in fungal biomass occurred when compared with the compatible interaction (Fig. 1B).

\subsection{Identification and molecular characterization of NtPK gene}

Four cDNA libraries were produced containing genes expressed during a compatible or incompatible interaction after inoculation with the corresponding $R$. solani strains. The sequence of 122 differentially expressed clones was used to search for homologies using BLASTX and BLASTN (Altschul et al., 1997).

Based on the homology displayed with sequences in public databases, and on expression in the compatible and incompatible interactions, 6 genes were further selected. These were only present in the cDNA library of expressed genes during incompatible interaction and that of repressed genes during compatible interaction. This was the main criterion for selecting only 6 genes for further analyses. Among these, only the NtPK gene exhibited a relative high level of expression in the incompatible compared to that in the compatible interaction in a separate experiment (Table 2). For the cytochrome P450, TBP, manganese superoxide dismutase, cell wallassociated hydrolase, mitogen-activated protein kinase and phospholipase B-like protein genes, the expression was induced compared to uninfected controls but somewhat similar levels of expression were found in both compatible and incompatible interactions at the same time points (Table 2 ). Therefore, we decided to study more closely the NtPK gene.

Sequence comparison analysis at the amino acid level showed that the NtPK is highly homologous with a N. tabacum protein kinase (Q40547). Some protein regions are highly conserved among the plant protein kinases (Fig. 2). However, it has been found that NtPK $\mathrm{N}$ - and C-termini domain are not conserved among the species analysed (Fig. 2).

\subsection{Functional analysis of NtPK gene in tobacco resistance to $R$. solani}

NtPK was overexpressed (Fig. 3A) or silenced in tobacco (Fig. 3B) and the resulting transformants lines were tested in a compatible and incompatible interaction with $R$. solani. In wild type tobacco, NtPK was induced during the incompatible and repressed during a

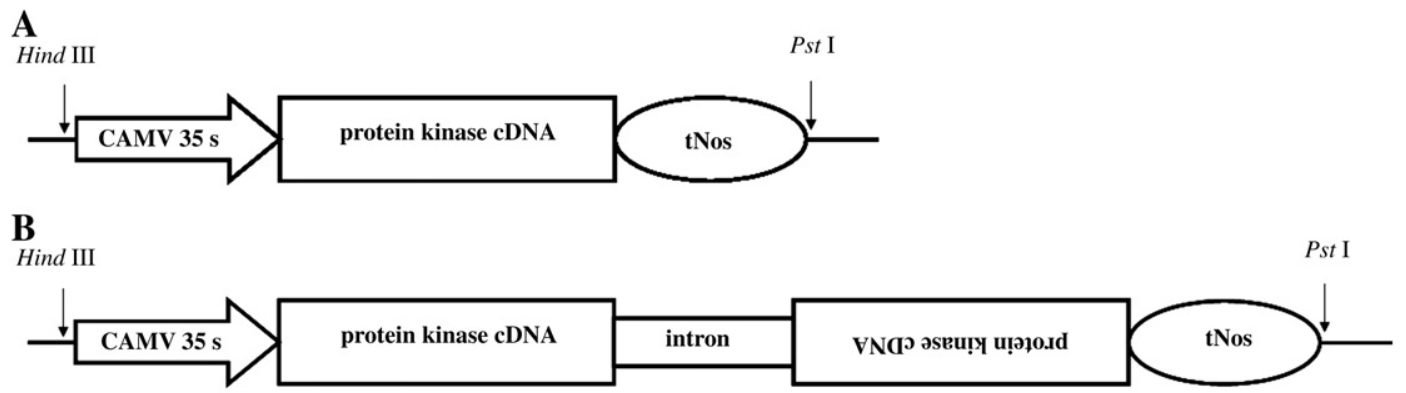

C

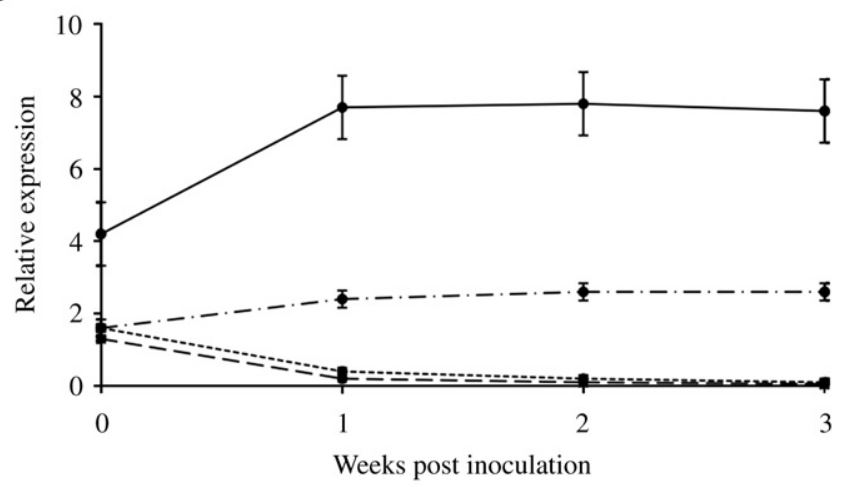

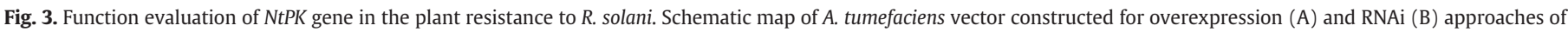

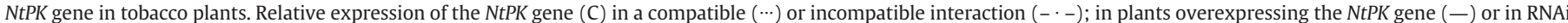
transformants silenced for NtPK (---). N=5; \pm SD. 
compatible interaction with $R$. solani, confirming the results obtained by subtractive hybridization (Fig. 3C). A significantly higher, respectively lower, level of NtPK transcript was observed in plants overexpressing NtPK or silenced for this gene (Fig. 3C). For these plants, overexpression, respectively silencing of the NtPK gene, enhanced or compromised the resistance to R. solani at 3 wpi (Fig. $4 \mathrm{~A}$ ), demonstrating the importance of the function of this gene for the resistance to $R$. solani. Interestingly, the disease symptoms produced by nonaggressive isolates were more severe in NtPK silenced plants (Fig. 4A) than in control plants inoculated with the same isolate (Fig. 4B) and the percentage of disease incidences was higher (Table 3 ). On the other hand, NtPK silenced plants inoculated with an aggressive isolate showed highest percentage of disease incidences (Table 3). Meanwhile, transformed plants overexpressing the NtPK gene showed a high level of resistance to aggressive $R$. solani isolate (Fig. 4A), compared to control plants inoculated with aggressive isolate (Fig. 4B) and the lowest percentage of disease incidences (Table 3). Using real-time PCR to quantify fungal biomass in the plant tissue it is evident that fungal biomass gradually increased in tobacco plants suppressing the NtPK gene inoculated with a nonaggressive isolate (Fig. 4C). Also, real-time PCR confirms that in tobacco plants overexpressing the NtPK gene inoculated with an aggressive isolate no significant increase in fungal biomass occurs when compared with tobacco plants suppressing the NtPK gene inoculated with a nonaggressive isolate (Fig. 4C). Additionally, tobacco plants suppressing the NtPK gene inoculated with an aggressive isolate had an increase in fungal biomass when compared with tobacco plants
Table 3

Disease incidences in tobacco plants overexpressing and suppressing the NtPK gene inoculated with R. solani.

\begin{tabular}{lc}
\hline Inoculation experiments & $\begin{array}{l}\text { Arcsine incidence } \\
(\%)^{\mathrm{a}}\end{array}$ \\
\hline $\begin{array}{l}\text { Tobacco plants overexpressing the NtPK gene inoculated } \\
\quad \text { with an aggressive isolate }\end{array}$ & 1.4 \\
Tobacco plants suppressing the NtPK gene inoculated with & 86.3 \\
$\quad$ a nonaggressive isolate & 96.4 \\
Tobacco plants suppressing the NtPK gene inoculated with & \\
$\quad$ an aggressive isolate & 92.5 \\
Control tobacco plants inoculated with an aggressive isolate & 1.8 \\
Control tobacco plants inoculated with a nonaggressive isolate & 4.5 \\
LSD $(0.05)^{\mathrm{b}}$ & 3.7 \\
CV $(\%)^{\mathrm{c}}$ & \\
\hline
\end{tabular}

\footnotetext{
a Arcsine-transformed percentage of disease incidence.

b Least significant difference.

c Coefficient of variation.
}

suppressing the NtPK gene inoculated with a nonaggressive isolate (Fig. 4C).

\subsection{Relative expression of several genes involved in plant disease resistance}

The relative level of expression of several genes associated with disease resistance was evaluated in tobacco plants overexpressing or silencing the NtPK gene. Tobacco plants overexpressing the NtPK

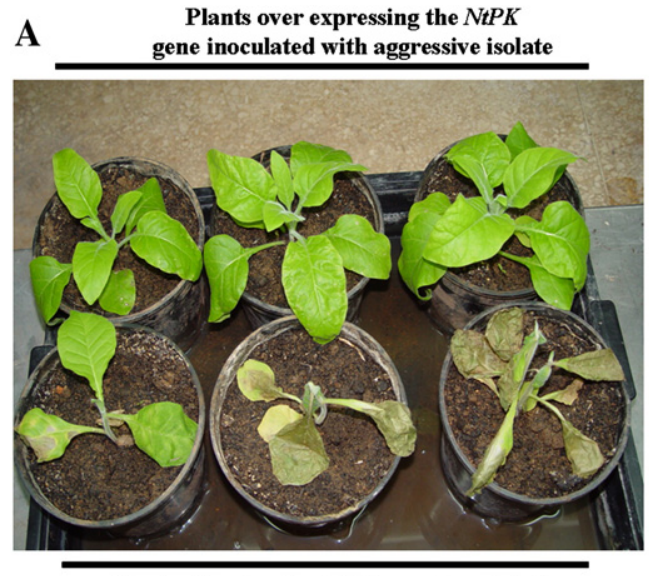

Plants silencing the $N t P K$ gene inoculated with non-aggressive isolate

B

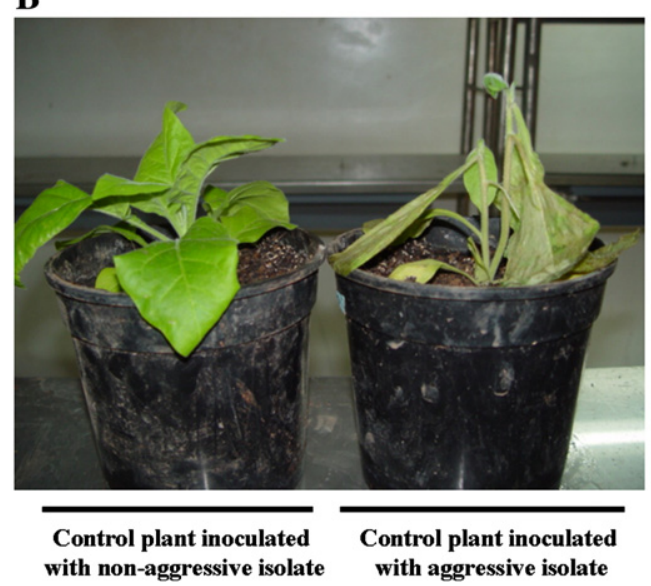

C

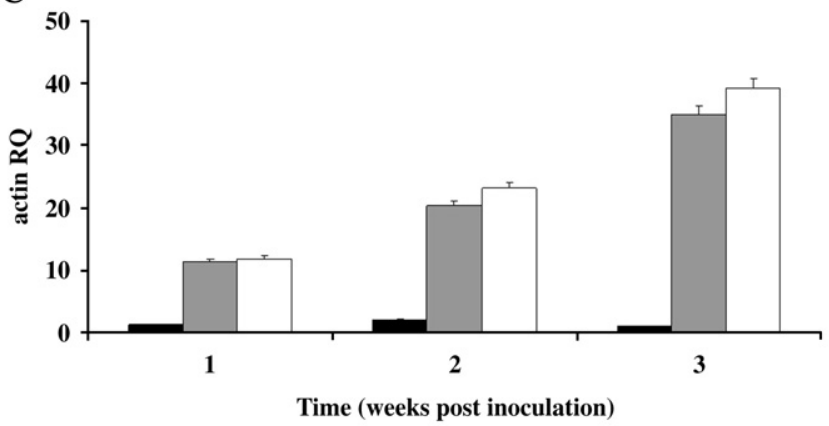

- Tobacco plants over expressing the NtPK gene inoculated with an aggressive isolate - Tobacco plants suppressing the NtPK gene inoculated with a non-aggressive isolate $\square$ Tobacco plants suppressing the NtPK gene inoculated with an aggressive isolate

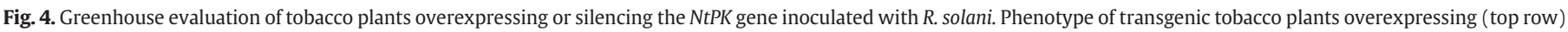

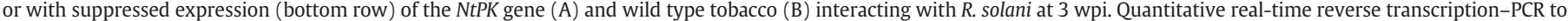
measure $R$. solani growth in tobacco plants overexpressing and suppressing the NtPK gene $(\mathrm{C})$. Bars represent mean values $(N=5$; $\pm \mathrm{SE})$. 
genes showed a quick and strong induction of manganese superoxide dismutase, Hsr203J, and chitinases genes starting at 1 wpi (Figs. 5A, C, and D). However, the expression of $\beta-1,3$ glucanase and phenylalanine ammonia-lyase genes reached their maximum expression at 2 wpi (Figs. 5B and D). All the genes analysed were differentially induced in plants overexpressing NtPK compared to the compatible interaction (Figs. 5A, C, D, and E). The expression of the $\beta-1,3$ glucanase gene was quite similar in both samples analysed (Fig. 5B).

Meanwhile, the regulation of these genes implicated in plant defense was evaluated in RNAi transformed lines for the NtPK gene. Manganese superoxide dismutase, Hsr203J, chitinases, and phenylalanine ammonia-lyase transcripts were found to be significantly induced during the incompatible interaction, compared to RNAi transformed lines where the expression was either delayed or lower (Figs. $6 \mathrm{~A}, \mathrm{C}, \mathrm{D}$, and $\mathrm{E}$ ). The expression of $\beta-1,3$ glucanase genes was similar in RNAi transformed lines and incompatible interaction (Fig. 6B). Because of their quick and strong induction in tobacco plants overexpressing the NtPK gene and the absence of their induction in the RNAi transformed lines, manganese superoxide dismutase, Hsr203J, chitinases and phenylalanine ammonia-lyase genes might contribute to the disease resistance phenotype of $N$. tabacum.
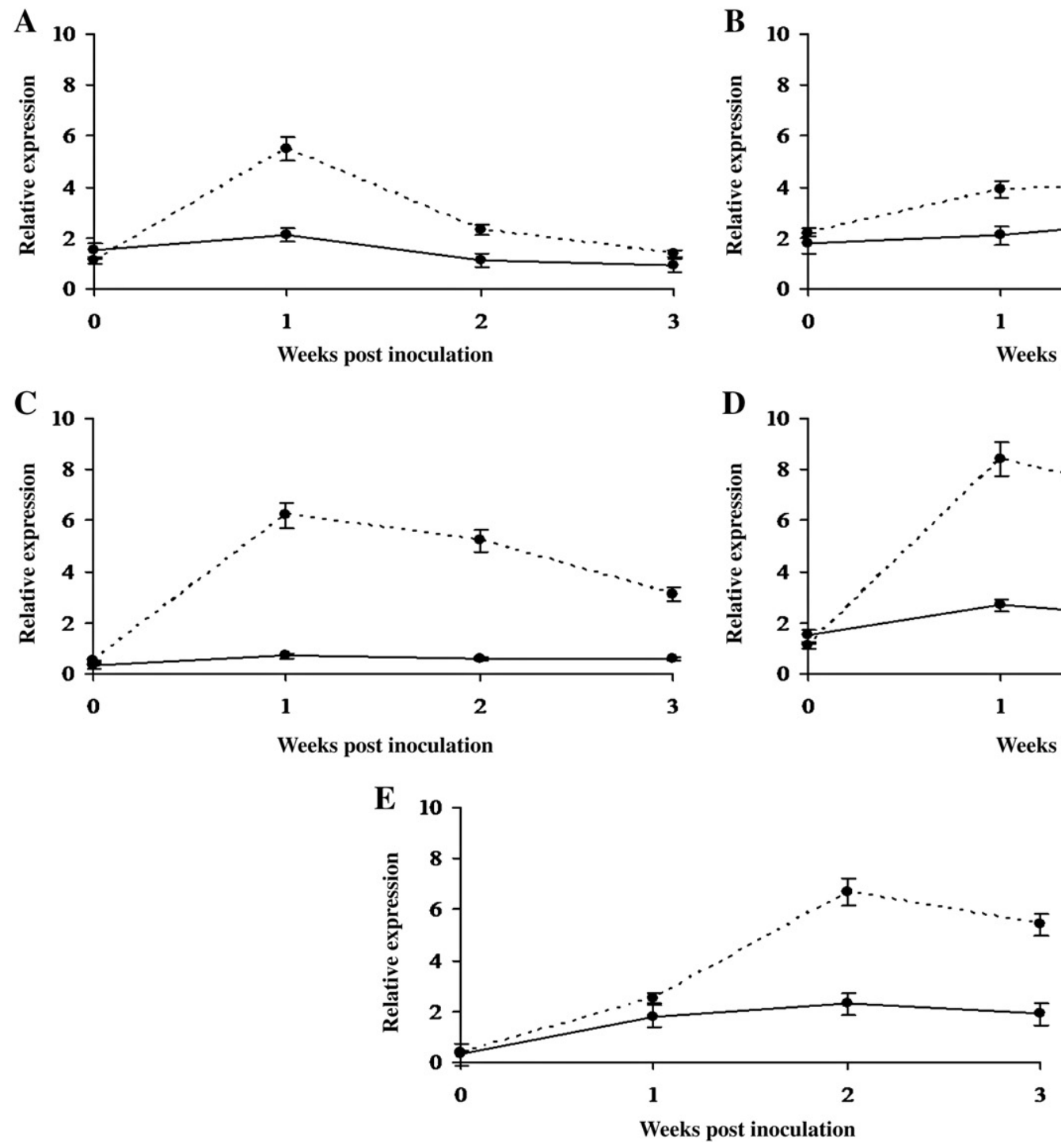

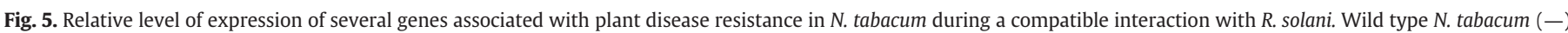

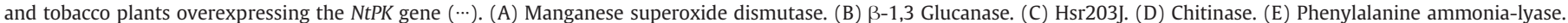
$N=5 ; \pm \mathrm{SD}$
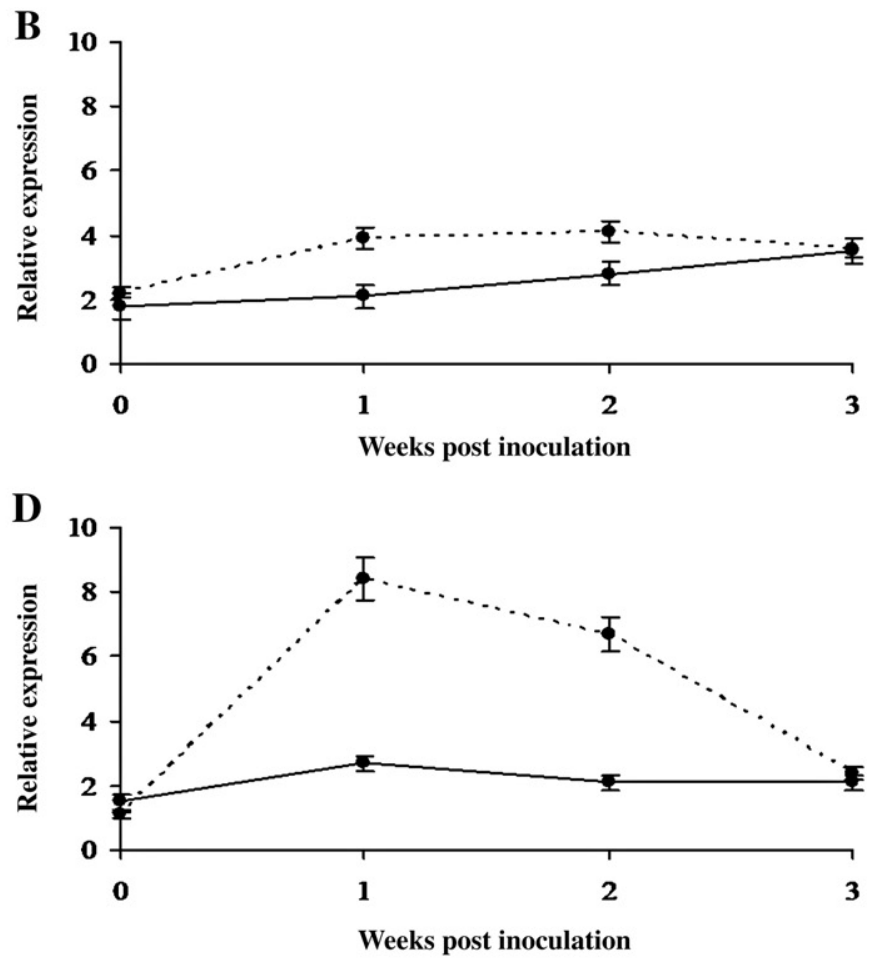

\section{Diseases produced by $R$. solani constitute a serious problem in field production of solanaceous plants (Elliott et al., 2008; Ceresini et al., 2002). Elliott et al. (2008) evaluated 97 genotypes belonging to several classes of tobacco and related Nicotiana spp. for seedling resistance to stem rot and target spot caused by $R$. solani and its teleomorph T. cucumeris. Significant differences in disease incidence were observed among the genotypes for both stem rot and target spot, but resistance to target spot was never observed when disease pressure was high (Elliott et al., 2008). This highlights the standing difficulty breeders experience with stem rot and target spot disease caused by $R$. solani. An important improvement for the future would be to engineer one or several genes into commercial varieties of tobacco or other crops to increase their natural potential for durable resistance against this soil-borne disease. \\ In this study, we have compared an interaction of N. tabacum cv. 'Sumatra' with aggressive strains or nonaggressive strains of $R$. solani (Fig. 1). Our goal was to find genes associated with the incompatible and compatible interaction, to isolate them and to test their biological relevance for resistance to $R$. solani. We reasoned that genes \\ 4. Discussion}

B

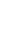 \\ (1)}



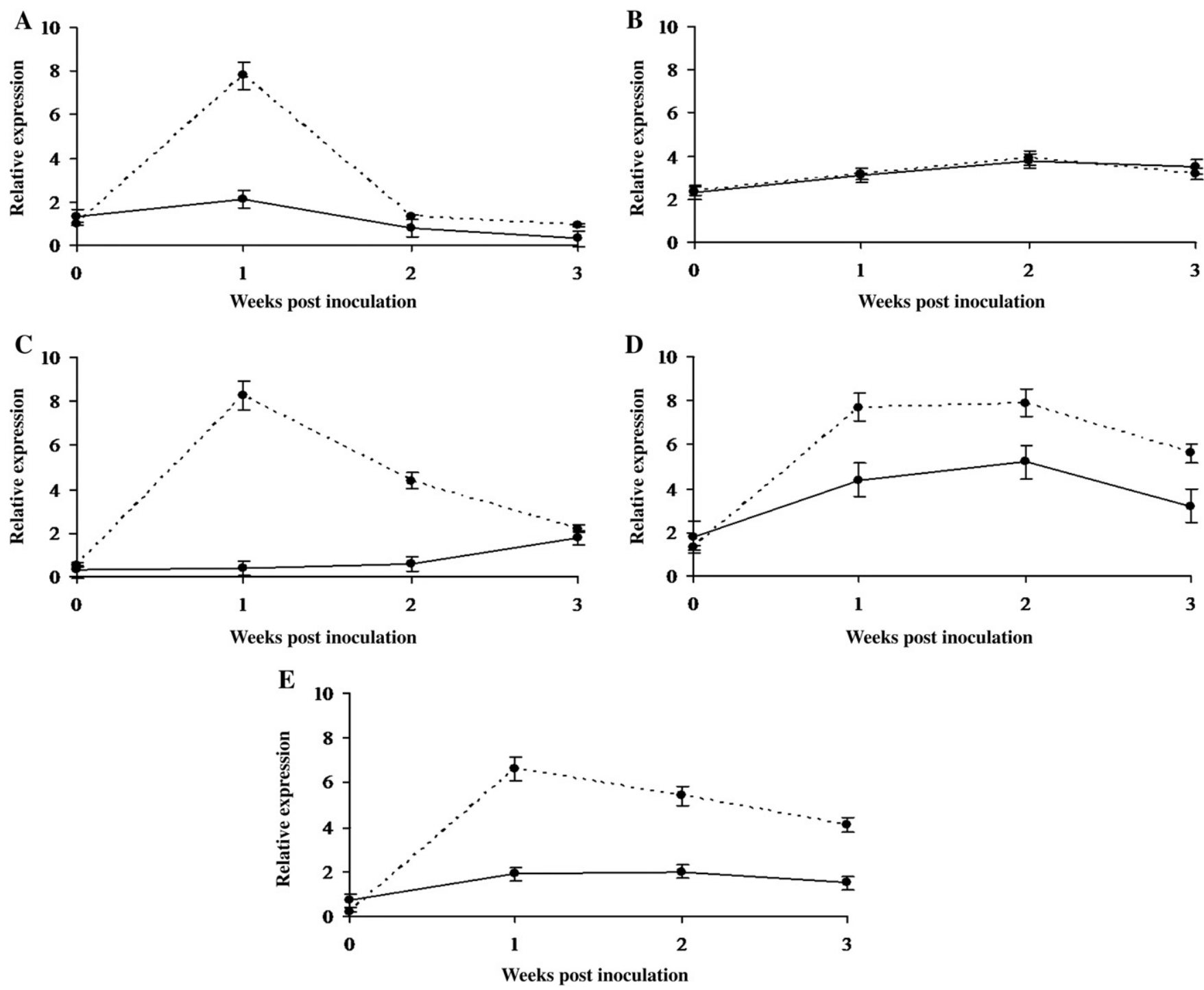

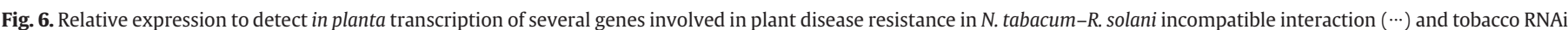

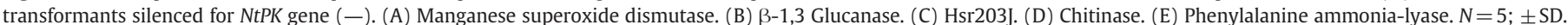

upregulated during an incompatible and downregulated during a compatible interaction might possibly be associated with defense of $N$. tabacum to R. solani. For that reason, candidates exhibiting such an expression pattern could be isolated and used for the assessment of their biological relevance by either overexpression or silencing in tobacco.

In this study, we have selected 122 cDNAs by subtractive hybridization that were differentially expressed in tobacco in four cDNA libraries during a compatible or an incompatible interaction with $R$. solani. Among these, only 6 cDNA clones were both present in the cDNA library of expressed genes during incompatible interaction and, at the same time, they were present in the cDNA library of repressed genes during compatible interaction. For that reason, we select only these genes for further analyses. However, only a gene encoding a protein kinase was repressed during the compatible and induced during the incompatible interaction in separate experiments (Table 2). After the subtracted cDNA library was obtained, to confirm that individual clones indeed represent differentially expressed genes and differential screening of the subtracted library in separate experiments was performed, to eliminate false-positives.

Tobacco plants overexpressing NtPK showed a high level of resistance to the aggressive $R$. solani isolate (Fig. 4B) and no growth of $R$. solani was observed up to 3 weeks after inoculation (Fig. 4C).
Conversely, suppression by RNAi led to a knockdown of the NtPK gene in N. tabacum and a compromised resistance against the nonaggressive $R$. solani strain (Fig. 4B). Taken together, these results indicate the importance of the NtPK gene in defense against $R$. solani (Figs. $4 \mathrm{~B}$ and $\mathrm{C}$ ).

Enzymes of the eukaryotic protein kinase superfamily catalyze the reversible transfer of the $\gamma$-phosphate from ATP to amino acid side chains of proteins. An estimated $1 \%$ to $3 \%$ of functional eukaryotic genes encode protein kinases, suggesting that they are involved in many aspects of cellular regulation and metabolism. In plants, protein phosphorylation has been implicated in responses to many signals, including light, pathogen invasion, hormones, temperature stress, and nutrient deprivation (Stone and Walker, 1995).

Within the protein kinase superfamily, the mitogen-activated protein kinase (MAPK) cascades play important roles in diverse developmental and physiological processes of plants, including pathogen-induced defense responses (Yuan et al., 2007). MAPKs are the central components that link MAPK cascades and downstream targets. Several MAPKs from different plant species have been demonstrated to play a role in pathogen-induced defense signal transduction by function complementary experiments. A few other MAPKs have been proposed to be involved in the regulation of defense responses because their expression is regulated by pathogens or elicitors. NtSIPK and NtWIPK, two early discovered MAPKs from 
tobacco, are involved in pathogen-induced defense responses (Zhang and Klessig, 1998, Romeis et al. 1999). The two MAPKs are activated by general and race-specific pathogens (Pedley and Martin, 2005). Arabidopsis AtMPK3 and AtMPK6 are homologues of tobacco NtWIPK and NtSIPK, respectively, and activation of these two MAPKs confers resistance to both bacterial and fungal pathogens (Zhang and Klessig, 2001, Asai et al. 2002).

At this time, no information is available on the precise biochemical function of the product of NtPK. Its possible position in a signalling cascade or more generally in the network for induced resistance needs to be determined.

Overexpressing of the NtPK gene in tobacco, lead to a higher expression of Hsr203J and superoxide dismutase (SOD), two genes that have been associated with hypersensitive response (HR)-like cell death. The gene HSR203 is regarded as a marker of the HR induced by a range of stimuli (Pontier et al. 1999, Gilroy et al. 2007). SOD converts superoxide radical to $\mathrm{H}_{2} \mathrm{O}_{2}$ and constitutes an essential component in an organism's defense mechanism against reactive oxygen species generated during various biotic and abiotic stresses (Scandalios, 1993, Asada, 1999, Badawi et al. 2004).

The higher SOD expression in the infected transgenic plants overexpressing the NtPK gene keeps the superoxide radical at lower level leading to reduced oxidative damage. In addition, the NtPK gene induced the expression of the phenylalanine ammonia-lyase (PAL) gene encoding a key enzyme in the pathway for phytoalexin and salicylic acid (SA) biosynthesis (Métraux, 2002). Besides Hsr203J, SOD and PAL, plants overexpressing NtPK also showed an increased expression of $\beta-1,3$ glucanase, and chitinase, two well-described genes encoding pathogenesis-related proteins. Interestingly, tobacco overexpressing a chitinase from bean has been reported to become more resistant to $R$. solani (Broglie et al. 1991). Possibly, the resistance we have observed in this study using overexpression results from a combined action of several gene products that might be under the direct or indirect control of NtPK.

The repression of the NtPK gene during a compatible interaction supports the tentative hypothesis that this gene might be under the control of pathogen-derived factors, e.g., suppressors. There is already good evidence for pathogen-derived suppressors of plant defenses in the case of other fungal plant interactions (Métraux et al., 2009). The observations presented here opens now the possibility to further study the possible mechanisms of a pathogen-derived suppression of a plant gene involved in defense.

In conclusion, the NtPK gene identified here appears to be involved in the defense response of tobacco to $R$. solani. This gene seems to be crucial for an efficient defense against $R$. solani might now be exploited in strategies to develop durable resistance in cultivated tobacco plants through either marker-assisted breeding or biotechnological approaches. Finally, it would be interesting to inoculate tobacco plants that are overexpressing the NtPK gene with $R$. solani isolates from other anastomosis groups to check if they show enhanced resistance.

\section{Acknowledgments}

We are grateful to the Swiss National Science Foundation for providing partial support of this research. The authors thank to anonymous reviewers and editor for useful suggestion.

\section{References}

Altschul, S.F., et al., 1997. Gapped BLAST and PSIBLAST: a new generation of protein database search programs. Nucleic Acids Res. 25, 3389-3402.

Anuratha, C.S., Zen, K.C., Cole, K.C., Mew, T., Muthukrishnan, S., 1996. Induction of chitinases and beta-1,3-glucanases in Rhizoctonia solani-infected rice plants: isolation of an infection-related chitinase cDNA clone. Physiol. Plant. 97, 39-46.

Asada, K., 1999. The water-water cycle in chloroplast: scavenging of active oxygen and dissipation of excess photons. Annu. Rev. Plant Physiol. Plant Mol. Biol. 50, 601-639.

Asai, T., et al., 2002. MAP kinase signaling cascade in Arabidopsis innate immunity. Nature 415, 977-983.
Ayala, M., et al., 2009. Production of plantibodies in Nicotiana plants. In: Faye, L., Gomord, V. (Eds.), Methods in Molecular Biology: Recombinant Proteins from Plants. Springer Science, Totowa, NJ, pp. 103-134.

Badawi, G.H., et al., 2004. Enhanced tolerance to salt stress and water deficit by overexpressing superoxide dismutase in tobacco (Nicotiana tabacum) chloroplasts. Plant Sci. 166, 919-928.

Bateman, D.F., 1964. An induced mechanism of tissue resistance to polygalacturonase in Rhizoctonia-infected hypocotyls of bean. Phytopathology 54, 438-445.

Bateman, D.F., Lumsden, R.D., 1965. Relation of calcium content and nature of the pectic substances in bean hypocotyls of different ages to susceptibility to an isolate of Rhizoctonia solani. Phytopathology 55, 734-738.

Broglie, K., et al., 1991. Transgenic plants with enhanced resistance to the fungal pathogen Rhizoctonia solani. Science 254, 1194-1197.

Ceresini, P.C., Shew, H.D., Vilgalys, R.J., Cubeta, M.A., 2002. Genetic diversity of Rhizoctonia solani AG-3 from potato and tobacco in North Carolina. Mycologia 94, 437-449.

Elliott, P.E., Lewis, R.S., Shew, H.D., Gutierrez, W.A., Nicholson, J.S., 2008. Evaluation of tobacco germplasm for seedling resistance to stem rot and target spot caused by Thanatephorus cucumeris. Plant Dis. 92, 425-430.

Francke, M.D., Brenneman, T.B., Holbrook, C.C., 1999. Identification of resistance to Rhizoctonia limb rot in a core collection of peanut germplasm. Plant Dis. 83, 944-948.

Gilroy, E., et al., 2007. Involvement of cathepsin B in the plant disease resistance hypersensitive response. Plant J. 52, 1-13.

Höfgen, R., Willmitzer, L., 1988. Storage of competent cells for Agrobacterium transformation. Nucleic Acid Res. 16, 9877.

Kenning, L.A., Hanchey, P., 1980. Ultrastructure of lesion formation in Rhizoctonia infected bean hypocotyls. Phytopathology 70, 998-1004.

Lucas, G.B., 1975. Diseases of Tobacco, 3rd ed. Biological Consulting Associates, Raleigh, NC.

Marshall, D.S., Rush, M.C., 1980. Infection cushion formation on rice sheaths by Rhizoctonia solani. Phytopathology 70, 947-950.

Métraux, J.P., 2002. Recent breakthroughs in the study of salicylic acid biosynthesis. Trends Plant Sci. 7, 332-334.

Métraux, J.P., Jackson, R.W., Schnettler, E., Goldbach, R., 2009, in: Van Loon, L.C. (Eds.) Plant Innate Immunity, Adv. Bot. Research.

Montoya, C.A., Beaver, J.S., Rodriguez, P.N., Miklas, P.N., Godoy-Lutz, G., 1997. Heritability of resistance of web blight in five common bean populations. Crop Sci. 37, 780-783.

Pan, X.B., et al., 1999. Major gene, nonallelic sheath blight resistance from the rice cultivars Jasmine 85 and Tequing. Crop Sci. 39, 338-346.

Pascual, C.B., Raymundo, A.D., Hyakumachi, M., 2000. Resistance of sorghum line CS 621 to Rhizoctonia solani AG1-IA and other sorghum pathogens. J. Gen. Plant Pathol. 66, 23-29.

Pedley, K.F., Martin, G.B., 2005. Role of mitogen-activated protein kinases in plant immunity. Curr. Opin. Plant Biol. 8, 541-547.

Pontier, D., Gan, S., Amasino, R.M., Roby, D., Lam, E., 1999. Markers for hypersensitive response and senescence show distinct patterns of expression. Plant Mol. Biol. 39, 1243-1255.

Reddy, M.N., 1980. Studies on groundnut hypocotyl exudates and the behavior of Rhizoctonia solani influencing the disease. Plant Soil 55, 445-454.

Romeis, T., Piedras, P., Zhang, S., Klessig, D.F., Hirt, H., Jones, J.D.G., 1999. Rapid Avr9and Cf9-dependent activation of MAP kinases in tobacco cell cultures and leaves: convergence of resistance gene, elicitor, wound, and salicylate responses. Plant Cell $11,27387$.

Scandalios, J.G., 1993. Oxygen stress and superoxide dismutases. Plant Physiol. 101, 7-12.

Scholten, O.E., Panella, L.W., De Bock, T.S.M., Wouter, L., 2001. A greenhouse test for screening sugar beet (Beta vulgaris) for resistance to Rhizoctonia solani. Eur. J. Plant Pathol. 107, 161-166.

Shew, H.D., 1991. Target spot. In: Shew, H.D., Lucas, G.B. (Eds.), Compendium of Tobacco Diseases. The American Phytopathological Society, St. Paul, MN.

Shew, H.D., Main, C.E., 1990. Infection and development of target spot of flue-cured tobacco caused by Thanatephorus cucumeris. Plant Dis. 74, 1009-1013.

Sneh, B., Jabaji-Hare, S., Neate, S., Dijst, G., 1996. Rhizoctonia Species: Taxonomy, Molecular Biology, Ecology, Pathology, and Disease Control. Kluwer Academic Publishers, Dordrecht, The Netherlands.

Stone, J.M., Walker, J.C., 1995. Plant protein kinase families and signal transduction. Plant Physiol. 8, 451-457.

Stevens, J.S., Jones, R.K., Shew, H.D., Carling, D.E., 1993. Characterization of populations of Rhizoctonia solani AG-3 from potato and tobacco. Phytopathology 83, 854-858.

Takabatake, R., Karita, E., Seo, S., Mitsuhara, I., Kuchitsu, K., Ohashi, Y., 2007. Pathogeninduced calmodulin isoforms in basal resistance against bacterial and fungal pathogens in tobacco. Plant Cell Physiol. 48, 414-423.

Thompson, J.D., Gibson, T.J., Plewniak, F., Jeanmougin, F., Higgins, D.G., 1997. The CLUSTAL X windows interface: flexible strategies for multiple sequence alignment aided by quality analysis tools. Nucleic Acids Res. 25, 4876-4882.

Yuan, B., Shen, X., Li, X., Xu, C., Wang, S., 2007. Mitogen-activated protein kinase OsMPK6 negatively regulates rice disease resistance to bacterial pathogens. Planta 226, 953-960.

Zhang, S., Klessig, D.F., 1998. $N$ resistance gene-mediated de novo synthesis and activation of a tobacco MAP kinase by TMV infection. Proc. Nat. Acad. Sci. U. S. A. 95, 7433-7438.

Zhang, S., Klessig, D.F., 2001. MAPK cascades in plant defense signaling. Trends Plant Sci. 6, 520-527. 